\title{
Laser treatment for post acne scars- A review
}

\author{
Keyal U, Huang $X,{ }^{1 *}$ Bhatta $A K^{1}$ \\ ${ }^{1}$ Department of Dermatology and Venereology, Tongji Hospital \\ affiliated to Tongji University School of Medicine, Shanghai, China
}

\begin{abstract}
*Corresponding Author:
Dr. Huang Xin, PhD, MD

Department of Dermatology and Venereology Associate Professor

Tongji Hospital affiliated to Tongji University

200065, Shanghai, China

Email: 1063132861@qq.com
\end{abstract}

\section{Citation}

Keyal U, Huang X, Bhatta AK. Laser treatment for post acne scars- A review. Nepal Journal of Medical Sciences 2013;2(2):165-70.

\begin{abstract}
Background: For years, there was no successful treatment for acne scars. Now, things have changed. With the development of new technologies, those suffering from acne scarring have multiple options to improve the tone and texture of the skin. Laser treatments, including ablative and non ablative laser skin resurfacing are among available treatment options.

Methods: The aim of writing this paper is to review information about acne scarring, as well as potential treatments by laser. The paper will first concentrate on introduction and classification of acne scarring, then go on to treatment modalities specifically by laser. This paper will also focus on post treatment recovery time, side effects and methods to prevent and treat those side effects.
\end{abstract}

Conclusion: Ultimate goal of any intervention in acne scarring is not total cure or perfection; rather it is making scars less visible.

Keywords: Acne scar; laser treatment; post treatment recovery

\section{Introduction:}

The term "scarring" refers to a process where collagen within the skin is damaged from inflammation, leading to permanent texture changes in the skin. Post acne scars are the result of compromised collagen production during the natural wound healing process, resulting in topographic depressions. Additionally, in skin with acne scarring, there are perpendicular bundles of collagen that anchor the skin of the scars. Histologically, post acne scars are usually limited to the epidermis and upper papillary dermis and, thus, amenable to treatment with a variety of techniques including ablative and non ablative lasers for skin resurfacing. Resurfacing procedures for many decades have been considered to have pre-eminence, but they should not be considered in isolation, and one needs to combine modalities to maximize outcomes. ${ }^{1}$ Given the dermal pathology present with acne scarring, particularly with atrophic scars, this condition can be difficult to treat effectively without using treatment modalities capable of affecting dermal remodeling at least 1 mm below the skin surface. ${ }^{2}$

\section{Classification of acne scar}

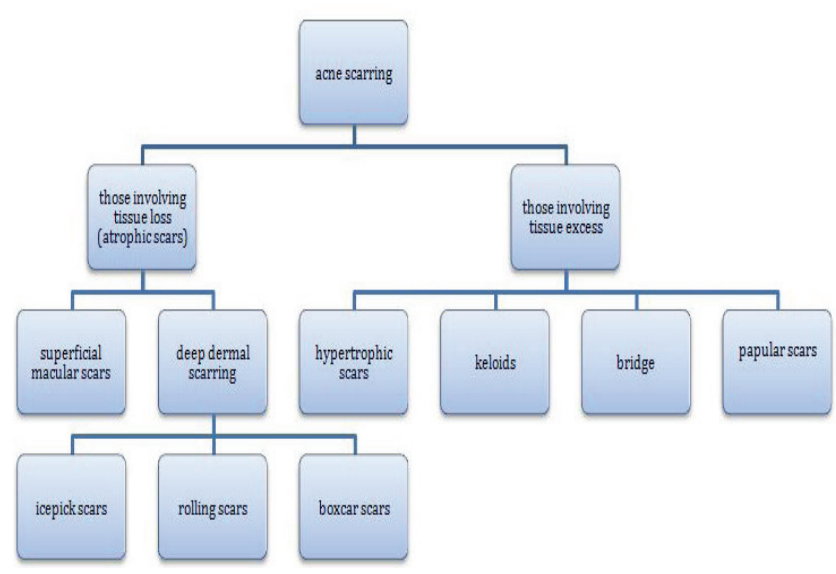

Figure 1 : Classification of acne scar 
1. Those involving tissue loss (Atrophic scars): Atrophic scars are broad, shallow, saucer-like indentations that result from loss of collagen deposition during the wound-healing process of acne lesions. They are more common than hypertrophic scars and keloids.

1.1. Superficial macular scars: These scars may appear as macules that may be discoloured, either erythematous if inflamed and comparatively early or young scars (under 1 year) or with altered pigmentation. Coloring or pigmentation of scars may be increased in patients with olive-colored skin and represents mostly a post- inflammatory response that will fade in 3-18 months. This requires sun protection. Reparative treatment may not always be required.

1.2. Deep dermal scarring: Includes icepick scars, rolling scars and boxcar scars. Ice-pick scars are frequently deeper, with sharp, steep sides. Rolling scars are caused by damage under the surface of the skin. They give the skin a wave-like appearance. They tend to be wide and shallow. Boxcar scars are angular scars with sharp vertical edges and are often found on cheeks and temples. They may be shallow or deep.

\section{Those involving tissue excess:}

2.1. Hypertrophic scars: Confined to the boundary of the original injury and increase in bulk by pushing out the margin. They are usually asymptomatic and develop within weeks after the injury and tend to resolve gradually. They tend to appear on the upper back, upper chest and deltoid region but can also appear on mandibular, malar and glabellar regions.

2.2. Keloids: They are irregularly shaped scars that extend beyond the borders of the original wound into adjacent tissue. They are often pruritic and tender. They are common in mandibular arch, shoulders and sternal region and are prone to recur.

2.3. Bridge: Bridge is a fibrous string over healthy skin. They are common on face.

2.4. Papular scars: They are soft elevations, like anetodermas and are frequently observed on the trunk and mental area.

Treatment for acne scarring by laser and its side effects

Acne scarring is permanent but can be treated. No treatment is $100 \%$ effective and the best result is improvement, not perfection. Treatment of scarring may require many different kinds of treatments, depending on the kind of scarring present. Treatment of acne scarring can be expensive and may not be covered by insurance. It is important that all the acne is clear before treating scarring. Many different treatments, including chemical peels, surgical excision, punch grafting, dermabrasion, and tissue augmentation with a variety of dermal fillers, have been used to improve atrophic acne scars with varying degrees of success. ${ }^{3,4}$

Over the last decade, laser skin treatments for acne scarring have been primarily centered on laser resurfacing with carbon dioxide (CO2) and erbium- doped yttrium aluminum garnet (Er:YAG) lasers. Although these lasers have proven effective in improving scar appearance through collagen remodeling and skin recontouring, they have been associated with extended recovery periods, prolonged erythema, hypo and hyper pigmentation, and in rare cases, induction of additional scarring. ${ }^{5,6}$ As a result of these potential risks and well-characterized adverse effects of ablative $\mathrm{CO} 2$ and Er:YAG laser resurfacing, non ablative laser technology using long- pulsed infrared (1,450-nm diode and 1,320-nm neodymium-doped yttrium aluminum garnet [Nd:YAG]) laser systems were developed as a safe alternative. ${ }^{7}$

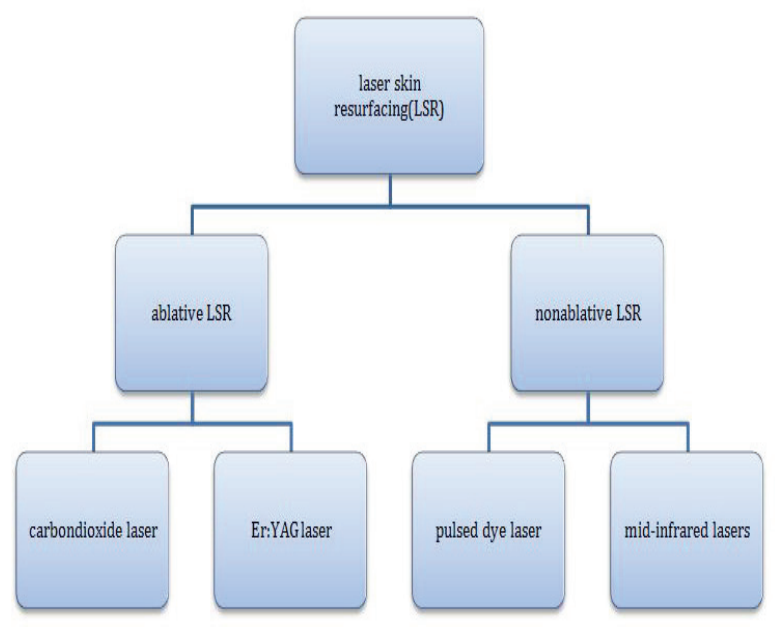

Figure 2: various options for laser treatment of acne scarring

\section{Ablative laser skin resurfacing}

\subsection{Carbondioxide Laser}

Skin resurfacing with the $\mathrm{CO} 2$ laser remains the gold standard technology for production of the most dramatic clinical and histologic improvement in severely photodamaged and scarred facial skin. ${ }^{8}$ producing a wavelength of $10,600 \mathrm{~nm}$,

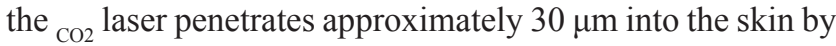
absorption and vaporization of water-containing tissue. Older continuous-wave $\mathrm{CO} 2$ lasers produced an unacceptable amount of thermal destruction (up to $200 \mu \mathrm{m}-2 \mathrm{~mm}$ beyond the target area). ${ }^{9}$ The new generation of pulsed and scanned $\mathrm{CO} 2$ lasers limit this thermal damage by delivery of high energy laser light with tissue dwell times shorter than the 
thermal relaxation time of the $30 \mu \mathrm{m}$ of targeted tissue (about $1 \mathrm{~ms}$ ). Use of the $\mathrm{CO} 2$ laser for skin resurfacing yields an additional benefit of collagen tightening through heating of dermal collagen. The triple helical structure of collagen is altered, resulting in shortening of the fibers by one third. ${ }^{10}$ Persistence of this collagen contraction results, in part, from these shortened fibers serving as a scaffold for neocollagenesis. Several CO2 laser systems are available and can be separated into two distinct groups: pulsed and scanned. CO2 laser has been used effectively to treat atrophic and other scars. ${ }^{11,12}$ Sculpting of scars with the laser yields a more uniform skin texture and stimulates new collagen formation within the dermal defects. Patients can expect a mean improvement of $50-80 \%$ in moderate atrophic scars, with continued collagen remodeling and scar effacement for $12-18$ months postoperatively. ${ }^{11,12}$ Patients with scars previously treated with dermabrasion or deep chemical peels may have additional fibrosis, which is more difficult to vaporize, thereby reducing their potential outcome. In addition, these patients also may have concealed hypopigmentation that could become more apparent after laser skin resurfacing. ${ }^{12,13}$ Although patients with paler skin tones are at lower risk for developing postoperative hyperpigmentation, those with darker skin tones can successfully undergo CO2 laser resurfacing.

\subsection{Erbium: Yttrium-Aluminum-Garnet Laser}

The emitted wavelength of $2,900 \mathrm{~nm}$ is absorbed $12-18$ times more efficiently by superficial cutaneous tissues, and approximately 2-5 $\mu \mathrm{m}$ of ablation occurs per pass with equally narrow zones of thermal necrosis. ${ }^{14}$ Clinically, this translates into a shorter postoperative healing time with much less post treatment erythema and risk of hyper pigmentation than CO2 lasers. However, immediate collagen contraction is only about $1-4 \%$, and long-term collagen remodeling ranges from $0-14 \%{ }^{8}$ Multiple passes with this laser are necessary to ablate to a similar depth as one pass of the $\mathrm{CO} 2$ laser, and because the Er:YAG effects are photomechanical instead of photothermal (like the CO2), intraoperative hemostasis is difficult to achieve. ${ }^{8,15}$ Therefore, the short-pulsed Er:YAG laser is limited in its utility for moderate-to-severe acne scars. Hybrid Er:YAG/CO2 laser systems (e.g., Derma-K, Lumenis, Santa Clara, CA, USA) are capable of delivering both $\mathrm{CO} 2$ energy for coagulation and Er:YAG energy for fine tissue ablation. The dual mode Er:YAG (e.g., Contour, Sciton, Palo Alto, CA, USA) combines short pulses (for ablation) with longer pulses (for coagulation). The variablepulsed Er:YAG (CO3, Cynosure, Chelms- ford, MA, USA) system has a range of pulse durations from $500 \mu$ s to 10 $\mathrm{ms}$, with the longer pulses effecting coagulation and thermal injury similar to the $\mathrm{CO} 2$ laser. ${ }^{16}$ As a group, these lasers have been shown to produce deeper tissue vaporization, greater control of hemostasis, and collagen contraction. This translates into greater clinical improvement in mildto-moderate acne scars than their short-pulsed predecessors and thus represent a good compromise between $\mathrm{CO} 2$ and earlier generation Er:YAG laser. ${ }^{17-21}$

\section{Adverse Effects and Complications of ablative LSR}

Side effects and complications are varied and greatly influenced by postoperative care, patient selection, and operator skill. In general, the side-effect profile after Er:YAG laser resurfacing is similar but less severe and more transient when compared with those experienced after $\mathrm{CO} 2$ laser resurfacing table $1.22-24$

Table 1: side effects and complications of ablative LSR

\begin{tabular}{cccc}
\hline Side effects & $\begin{array}{c}\text { Mild } \\
\text { complications }\end{array}$ & $\begin{array}{c}\text { Moderate } \\
\text { complications }\end{array}$ & $\begin{array}{c}\text { Severe } \\
\text { complications }\end{array}$ \\
\hline $\begin{array}{c}\text { Transient } \\
\text { erythema }\end{array}$ & $\begin{array}{c}\text { Prolonged } \\
\text { erythema }\end{array}$ & $\begin{array}{c}\text { Pigmentary change } \\
\text { Localized } \\
\text { edema }\end{array}$ & $\begin{array}{c}\text { Hypertrophic } \\
\text { scar }\end{array}$ \\
Mruritus & Acne & $\begin{array}{c}\text { Infection (bacterial, } \\
\text { viral, fungal) }\end{array}$ & Ectropion \\
& Contact & Hypopig- \\
& mentation \\
& dermatitis & & \\
\hline
\end{tabular}

Postoperative erythema, lasting an average of 4.5 months, is an expected occurrence in all $\mathrm{CO} 2$ laser treated patients and is a normal consequence of the wound healing process. Degree of erythema correlates directly with the depth of ablation and number of laser passes performed. ${ }^{25,26}$ It may also be aggravated by underlying rosacea or dermatitis. Topical agents like retinoic acid derivatives, glycolic acid, fragrance or chemical containing cosmetics and sunscreens should be strictly avoided in early postoperative period until substantial healing has occurred. ${ }^{25}$ Mild side effects includes milia formation and acne exacerbation, which may be caused by the postoperative use of occlusive dressings and ointments particularly in patients who are acne prone. ${ }^{25-29}$ Milia and acne usually resolve spontaneously as healing progresses and application of thick emollient creams and occlusive ceases. Oral antibiotics may be prescribed for acne flares that do not respond to topical preparation..$^{25,29,30}$ Wound infections associated with ablative laser resurfacing include staphylococcus and pseudomonas infections and cutaneous 
candidiasis and should be treated aggressively with an appropriate systemic antibiotic or antifungal agent. ${ }^{31}$ The most common infectious complication is a reactivation of labial HSV infection..$^{25,27}$ Therefore all patients undergoing full-face or perioral ablative resurfacing should receive antiviral prophylaxis even if they report no history of HSV infection. Patients should begin prophylaxis by the day of surgery and continue it for 7 to 10 days postoperatively. ${ }^{32}$ Hyperpigmentation is one of the more common side effects and occurs to some degree in all patients with darker skin tones. ${ }^{31,33}$ The reaction is transient but its resolution can be hastened with use of topical agents like hydroquinone and retinoic, azelaic, kojic, and glycolic acid. Hypopigmentation is particularly intractable to treatment. The use of an eximer laser or topical photochemotherapy to stimulate repigmentation has proven successful in some patients. ${ }^{34,35}$ The most severe complications includes hypertrophic scars and ectropion formation. ${ }^{33,36}$ Focal areas of bright erythema with pruritus, particularly along the mandible, may signal impending scar formation. ${ }^{32,37}$ Potent topical corticosteroid preparations should be applied to decrease inflammatory response. A pulsed dye laser can also be used to improve the appearance and symptoms of laser induced burn scars. ${ }^{38}$ Ectropion of lower eyelid is rarely seen but, if encountered, usually requires surgical correction. ${ }^{28}$ In general, lower fluences and fewer laser passes should be applied in the periorbital area to decrease the risk of lid eversion.

Side effects and complications after Er:YAG laser resurfacing are similar to those observed after $\mathrm{CO} 2$ laser skin resurfacing but they differ in duration, incidence, and severity.$^{39,40}$

\section{Nonablative laser skin resurfacing}

While ablative skin resurfacing with $\mathrm{CO} 2$ and Er:YAG lasers has been proven highly efficacious in reversing the signs of atrophic scars, the associated lifestyle hindrance and potential complications are often unacceptable to patients. In recent years, focus has shifted towards nonablative technologies that deliver either laser, light based, or radiofrequency energies to the skin.

\subsection{Pulsed Dye Laser}

Used predominantly for the treatment of hypertrophic scars. ${ }^{41,42}$ The most common side effects include mild edema, purpura, and transient post inflammatory hyperpigmentation. It has been hypothesized that the selective heating of dermal vessels leads to release of endothelial-derived growth factors and cytokines that up-regulate fibroblasts in treated skin, thereby resulting in neocollagenesis.

\subsection{Mid-infrared lasers}

Laser systems operating in the mid infrared portion of the electromagnetic spectrum, including the $1320 \mathrm{~nm}$ $\mathrm{Nd}$ :YAG, $1450 \mathrm{~nm}$ diode, and 1540 Er:Glass lasers, possess optimal wave lengths for water-based non-ablative skin remodeling. ${ }^{43}$ The majority of ultraviolet induced sun damage occurs at dermal depths of 100-400 um and, because the water absorption coefficient is low at wavelengths longer than $700 \mathrm{~nm}$, infrared lasers $(>1000 \mathrm{~nm})$ are able to better deliver energy at these tissue depths. ${ }^{44}$

To protect the epidermis, dynamic cooling is employed. The hand piece contains a thermal sensor to assist in maintaining the epidermal temperature below $50^{\circ} \mathrm{C}$. At $40-45^{\circ} \mathrm{C}$, the dermis is heated to a temperature reached of $60-65^{\circ} .44,45$ The latest generation of the 1320nm Nd:YAG laser (Cool Touch II, ICN Pharmaceuticals, Costa Mesa, CA) delivers energies ranging $28-38 \mathrm{~J} / \mathrm{cm} 2$ with a pulse duration of $350 u s$ through a $10 \mathrm{~mm}$ spot size hand- piece. Treatments are usually performed every month for a series of at least three sessions. Multiple studies have shown efficacy in the treatment of atrophic facial scars with only mild edema and erythema post-procedure. ${ }^{45,46}$ A study comparing the 1320 $\mathrm{nm} \mathrm{Nd}$ :YAG to the $1450 \mathrm{~nm}$ diode laser for treatment of atrophic acne scars revealed that the $1450 \mathrm{~nm}$ laser effected more significant change in the scar appearance and skin texture. ${ }^{46}$ Both mid-infrared lasers, however, induced clinical improvement. With the additional positive effect of the 1450 $\mathrm{nm}$ diode laser on active acneiform lesions, ${ }^{47}$ this system may be preferable for those patients with concomitant acne and atrophic facial scars.

\section{Side effects and complications of non ablative lasers.-} Ablative Lasers/ R

Side effects of non-ablative laser treatments are generally mild and transient. Local erythema and edema are typically observed in treated skin; however, a small percentage of patients in these studies experience superficial burns, ecchymoses, dysesthesias, and vesiculation. ${ }^{48,49-52}$ In some cases, post treatment hyperpigmentation has been caused by excessive use of cryogen spray but has resolved with topical bleaching agents. To avoid reactivation of latent HSV infections, appropriate oral antiviral prophylaxis should be considered for all patients regardless of reported HSV status.

\section{Conclusion:}

Laser treatment has revolutionized the approach to acne 
scarring but it has yet a long way to go in order to get more satisfying results in short time. The Results after treatment will disappoint patients who desire dramatic improvement in a short period of time. Additionally, although these technologies have a much lower side effect profile, they are not devoid of risks. Ultimate goal of any intervention in acne scarring is not total cure or perfection; rather it is making scars less visible. Selection of appropriate technique requires that patient factors as well as the risks and benefits of the procedure be weighed.

\section{References:}

1. Goodman GJ. The limitations of resurfacing techniques the necessity to combine procedures. Dermatol Surg 1998;24:687-8.

2. Jordan R, Cummins C, Burls A. Laser resurfacing of the skin for the improvement of facial acne scarring: a systematic review of the evidence. $\mathrm{Br} \mathrm{J}$ Dermatol 2000;142:413-23.

3. Kaplan EN, Falces E, Tolleth H. Clinical utilization of injectable collagen. Ann Plast Surg 1983;10:437-51.

4. Moritz DL. Surgical correction of acne scars. Dermatol Nurs 1992;4:291-9.

5. Alster TS. Cutaneous resurfacing with $\mathrm{CO} 2$ and erbium: YAG lasers: preoperative, intraoperative, and postoperative considerations. Plast Reconstr Surg 1999;103:619-32; discussion 633-4.

6. Walia S, Alster TS. Prolonged clinical and histologic effects from $\mathrm{CO} 2$ laser resurfacing of atrophic acne scars. Dermatol Surg 1999;25:926-30.

7. Tanzi EL, Alster TS. Comparison of a 1,450-nm diode laser and a 1,320-nm Nd:YAG laser in the treatment of atrophic facial scars: a prospective clinical and histologic study. Dermatol Surg 2004;30:152-7.

8. Alster TS. Cutaneous resurfacing with $\mathrm{CO} 2$ and Erbium:YAG lasers; preoperative, intraoperative, and postoperative considerations. Plast Reconstr Surg 1999;103:619-32.

9. Lanzafame RJ, Naim JO, Rogers DW, et al. Comparisons of continuous wave, chop wave, and superpulsed laser wounds. Lasers Surg Med 1988;8:119-24.

10. Ross E, Naseef G, Skrobal M, et al. In vivo dermal collagen shrinkage and remodeling following $\mathrm{CO} 2$ laser resurfacing. Lasers Surg Med 1996;18:38.

11. Walia S, Alster TS. Prolonged clinical and histologic effects from $\mathrm{CO} 2$ laser resurfacing of atrophic acne scars. Dermatol Surg 1999;25:926-30.

12. Alster TS, West TB. Resurfacing of atrophic facial acne scars with a high energy, pulsed carbon dioxide laser. Dermatol Surg 1996;22:151-4.

13. Alster TS, Lupton JR. Prevention and treatment of side effects and complications of cutaneous laser resurfacing. Plast Reconst Surg 2002;109:308-16.

14. KaufmannR, Hibst R. Pulsed erbium:YAG laser ablation in cutaneous surgery. Lasers Surg Med 1996;19:32430.

15. Walsh JT Jr, Deutsch TF. Er:YAG laser ablation of tissue: Measurement of ablation rates. Lasers Surg Med 1989; 9:327-37.

16. Sapijaszki MJA, Zachary CB. Er:YAG laser skin resurfacing. Dermatol Clin 2002;20:87-96.

17. Tanzi EL, Alster TS. Treatment of atrophic facial acne scars with a dual mode Er:YAG laser. Dermatol Surg 2002; 15:33-6.

18. Trelles MA, Mordon S, Benitez V, et al. Er:YAG laser resurfacing using combined ablation and coagulation modes. Dermatol Surg 2001; 27 :727-34.

19. Rostan EF, Fitzpatrick RE, Goldman MP. Laser resurfacing with a long pulse Erbium : YAG laser compared to the $950 \mathrm{~ms}$ pulsed CO2 laser. Lasers Surg Med 2001;29:136-41.

20. AlsterTS, LuptonJR. Erbium:YAG cutaneous laser resurfacing. Dermatol Clin 2001;19:453-66.

21. Teikemeier G, Goldberg DJ. Skin resurfacing with the erbium:YAG laser. Dermatol Surg 1997;23:685-7.

22. Tanzi EL, Alster TS. Single pass carbon dioxide versus multiple pass Er:YAG laser skin resurfacing : a comparison of postoperative wound healing and side effect rates. Dermatol Surg 2003;29:80-4.

23. TanziEL, AlsterTS. Side effects and complications of variable-pulsed Erbium : Yttrium-Aluminum-Garnet laser skin resurfacing: extended experience with 50 patients. Plast Reconstr Surg 2003;111:1524-9.

24. Nanni CA, Alster TS. Complications of carbon dioxide laser resurfacing: An evaluation of 500 patients. DermatolSurg 1998;24:315-20.

25. Nanni CA, Alster TS. Complications of carbondioxide laser resurfacing: an evaluation of 500 patients. Dermatol Surg 1998;24:315-20.

26. Alster TS. Cutaneous resurfacing with $\mathrm{CO} 2$ and erbium:YAG lasers: preoperative, intraoperative, and 
postoperative considerations. Plast Reconstr Surg 1999;103:619-32.

27. Bernstein LJ, Kauvar AN, Grossman MC, et al. The short and long term side effects of carbon dioxide laser resurfacing. Dermatol Surg 1997;23:519-25.

28. Alster TS, Lupton JR. Prevention and treatment of side effects and complications of cutaneous laser resurfacing. Plast Reconst Surg 2002;109:308-16.

29. Horton S, Alster TS. Preoperative and postoperative considerations for cutaneous laser resurfacing. Cutis 1999; 64:399-406.

30. Waldorf HA, Kauvar ANB, Geronemus RG. Skin resurfacing of fine to deep rhytides using a charfrecarbon dioxide laser in 47 patients. Dermatol Surg 1995;21:940-6.

31. Sriprachya-anunt S, Fitzpatrick RE, Goldman MP, et al. Infections complicating pulsed carbon dioxide laser resurfacing for photo-aged facial skin. Dermatol Surg 1997;23:527-36.

32. Alster TS, Tanzi EL. Complications in laser and light surgery. In: Laser Skin Surgery, vol. 2, edited by DB Goldberg. Philadephia, Elsevier, Inc., 2005, pp. 103118

33. Alster TS. Commentary on: Increased smooth muscle actin, factor XIII a, and vimentin positive cells in the papillary dermis of carbon dioxide laser-debrided porcine skin. Dermatol Surg 1998;24:155.

34. Friedman PM, Geronemus RG. Use of the 308-nm excimer laser for post resurfacing leukoderma. Arch Dermatol 2001;137:824-25.

35. Grimes PE, Bhawan J, Kim J, et al. Laser resurfacing induced hypopigmentation: histologic alteration and repigmentation with topical photochemotherapy. Dermatol Surg 2001;27:515-20.

36. Ruback BW, Schroenrock LD. Histological and clinical evaluation of facial resurfacing using a carbon dioxide laser with the computer pattern generator. Arch Otolaryngol Head Neck Surg 1997;123:929-34.

37. Graber EM, Tanzi EL, Alster TS. Side effects and complications of fractional laser photothermolysis: experience with 961 treatments. DermatolSurg 2008;4:301-7.

38. Alster TS, Nanni CA. Pulsed dye laser treatment of hypertrophic burn scars. Plast Reconstr Surg 1998;102:2190-5.
39. Ross VE, Miller C, Meehan $\mathrm{K}$ et al. One-pass CO2 versus multiple-pass Er:YAG laser resurfacing in the treatment of rhytides: a comparison side by side study of pulsed CO2 and Er:YAG lasers. Dermatol Surg 2001;27:709-15.

40. Zachary CB. Modulating the Er:YAG laser. Lasers Surg Med 2002;26:223-6.

41. Tanzi EL, Lupton JR, Alster TS. Review of lasers in dermatology: four decades of progress. J Am Acad Dermato 2003;14:1-31.

42. Lupton JR, Alster TS. Laser scar revision. Dermatol Clin 2002;20:55-65 .

43. Alster TS, Tanzi EL. Benign manifestations of photodamage: laser and light source treatment. In: Goldberg DB (ed) Photodamaged Skin. Marcel DekkerInc, New York, pp 2004; 115-43.

44. Hardaway CA, Ross EV. Non-ablative laser skin remodeling. Dermatol Clin 2002;20:97-111.

45. Kelly KM, Nelson JS, Lask GP, et al. Cryogen spray cooling in combination with nonablative laser treatment of facial rhy- tides. Arch Dermatol 1999;135:691-4.

46. Tanzi EL, Alster TS. Comparison of a $1450 \mathrm{~nm}$ diode laser and a $1320 \mathrm{~nm} \mathrm{Nd}$ : YAG laser in the treatment of atrophic facial scars:a prospective clinical and histologic study. Dermatol Surg 2004;30:152-7.

47. Paithankar DY, Ross EV, Saleh BA, et al. Acne treatment with a $1450 \mathrm{~nm}$ wavelength laser and cryogen spray cooling. Lasers Surg Med 2002;31:106-14.

48. Tanzi EL, Alster TS. Treatment of facial rhytides with a 1450-nm diode laser: A controlled clinical and histologic study. Dermatol Surg 2003;29:124-8.

49. Ruiz Esparza J, Gomez JB. The medical facelift: a noninvasive, nonsurgical approach to tissue tightening in facial skin using nonablative radiofrequency. Dermatol Surg 2003;29:325-32.

50. Fitzpatrick R, Geronemus R, Goldberg D, et al. First multicenter study of noninvasive radiofrequency for periorbital tissue tightening. Laser Surg Med 2003;33:232-42.

51. Hsu TS, Kaminer MS. The use of nonablative radiofrequency technology to tighten the lower face and neck. Semin Cutan Med Surg 2003;22:115-23.

52. Alster, TS, Tanzi EL. Improvement of neck and cheek laxity with a nonablative radiofrequency device: a lifting experience. Dermatol Surg 2004;30:503-7. 